\title{
Viagens acadêmicas como registro do Patrimônio: A cidade de Penedo nas margens do São Francisco
}

\author{
Academic trips as Heritage registration: City of Penedo along the Sao Francisco \\ River
}

\author{
Eder Donizeti da Silva ${ }^{1 *}$, Adriana Dantas Nogueira ${ }^{2}$
}

\begin{abstract}
RESUMO
Este artigo apresenta o relato das viagens acadêmicas realizadas entre 2016 e 2019 à cidade histórica de Penedo, às margens do Rio São Francisco, que teve como prerrogativa a atividade extensionista com alunos do curso de Arquitetura e Urbanismo da Universidade Federal de Sergipe, alunos da Oficina Escola de ensino de conservação e restauro da Cidade de Laranjeiras. Objetivo de conhecer in situ a história da arquitetura brasileira, uma vez que os monumentos e edificações visitados guardam a identidade e memória de vários períodos históricos. A investigação propiciou experiências de extremo valor prático, como a percepção da técnica ilusionista renascentista presente na pintura no forro da Igreja de Santa Maria dos Anjos, entre outras, além do contato com as rotinas necessárias às ações de intervenção (conservação e restauro) de edifícios portadores de juízo de valor patrimonial. Observações que ativaram a relação de identidade e memória do indivíduo com o meio, predispondo a formação mais completa de arquitetos e técnicos como agentes difusores multiplicadores da preservação, prevenção, conservação e restauro do patrimônio cultural.
\end{abstract}

Palavras-chave: Viagens; Urbanismo; História; Preservação; Patrimônio

\begin{abstract}
This paper presents the report of academic trips carried out between 2016 and 2019 to the historic city of Penedo, on the banks of the São Francisco River, whose prerogative was the extension activity with students of the Architecture and Urbanism course at the Federal University of Sergipe and students of the Conservation and restoration teaching school Workshop in the City of Laranjeiras. Objective of knowing in situ the history of Brazilian architecture since the monuments and buildings visited keep the identity and memory of various historical periods. The investigation provided experiences of extreme practical value, such as the perception of the Renaissance illusionist technique present in the painting on the ceiling of the Church of Santa Maria dos Anjos, among others, in addition to the contact with the necessary routines for intervention actions (conservation and restoration) of buildings holders of equity value judgment. Observations that activated the individual's relationship of identity and memory with the environment, predisposing the more complete training of architects and technicians as diffusing agents for the preservation, prevention, conservation, and restoration of cultural heritage.
\end{abstract}

Keywords: Trips; Urbanism; History; Preservation; Heritage

\footnotetext{
${ }^{1}$ Universidade Federal de Sergipe. *E-mail: eder@infonet.com.br

${ }^{2}$ Universidade Federal de Sergipe
} 


\section{INTRODUÇÃO}

Na história da Arquitetura e Urbanismo, verifica-se uma constante discussão entre a teoria e prática em como construir belas edifícações e implantar cidades eficientes, os teóricos antigos e os modernos indicam que o arquiteto deve unir este dois preceitos, no entanto, outro ingrediente, às vezes pouco ou quase nunca estudado, é introduzido nesta intenção da busca de apreender arquitetura, ou seja, a necessidade de observação de obras já realizadas em locais e cidades que se tornaram exemplos emblemáticos para a fruição e compreensão de um modelo a ser seguido, ou mesmo que, com o tempo, tornaram-se a representação da identidade e memória arquitetônica de uma época; estes locais e edificações passam a ser, então, foco e sonho de uma visitação obrigatória na formação do arquiteto.

\section{O APRENDIZADO DO VER O URBANISMO E A ARQUITETURA}

Pontuando que as lições de arquitetura partem das leituras históricas e teóricas e de sua influência sobre o criar edificações e espaços urbanos e que a pretensa "descoberta" do Brasil ocorreu na transição do Renascimento para o Maneirismo, apesar de os Portugueses não terem inicialmente a intenção de se fixar, deixaram marcadas técnicas e estéticas ao longo de 300 anos (BURY, 1991, p.162). Devemos admitir, além dos portugueses, a influência indígena nos cem primeiros anos da Colônia (WEIMER, 2018, p.202), dos negros nos séculos vindouros (WEIMER, 2014, p.156), dos franceses, holandeses (HUE, 1999, p.20) e depois nos revivais historicistas (FABRIS, 1987, p.122), da arquitetura Moderna Alemã e Francesa no século XX (SEGAWA, 1997, p.41); nesta trajetória, exemplos de edificações e espaços urbanos variados pontuaram, mesmo que a distância, a forma do fazer e foram usados como modelos e tipologias a serem seguidos no Brasil.

Quanto ao sistema construtivo, as lições de Vitrúvio (POLIÃO, 1999, p.69-70) estiveram presentes, como na observação dos materiais de construção, adobes, cal, pedras, madeiras, na observação da disputa técnica entre a tradição e o jeito de fazer, do exercício da imaginação e do engenho dos locais, das formas dos arcos, abobadas, colunas, ordens, da influência da natureza e da própria engenhosidade humana. Outros 
aspectos técnicos também foram cuidados por outros teóricos ao longo do tempo, como o entendimento construtivo das torres como elemento de maior dificuldade na edificação das Igrejas, a disposição geométrica das plantas baixas, os elementos ornamentais e suas decorações como folhagens, cartelas, brasões, cartuchas, coruchéus, esculturas, carrancas, elementos ornamentais "abrasileirados" nos tímpanos dos frontões e no riscado do frontispício das igrejas ou nas talhas dos linteis e/ou ombreiras das portadas (RODRIGUES, 1975, p.138).

O aprendizado da arquitetura também se inscreve no exercício do conhecimento histórico e teórico de suas tipologias, da arquitetura militar, civil e religiosa. A arquitetura militar esteve muito presente no Brasil entre 1500 e 1800, essas construções tiveram importância no recrudescimento da defesa e estabelecimento da posse da terra pela metrópole. Um dos nomes mais importantes foi o do Português Francisco de Frias da Mesquita (SILVA-NIGRA, 1945, p. 9), que entre muitas fortificações e construções religiosas, trabalhou na Fortaleza dos Reis Magos na atual Cidade de Natal/RN (SILVANIGRA, Op.cit., p.13). As fortificações podem ser consideradas como as que menos sofreram alterações construtivas de transição para o Brasil.

$\mathrm{Na}$ arquitetura civil brasileira, alguns dos modelos históricos e teóricos estudados são a Nobre Morada de Garcia D’Ávila (RODRIGUES, 1945, p.164), a Morada Seiscentista Paulista (SMITH, 1969, p. 27). A estreita relação dessas construções com as economias que monopolizaram o período colonial, como o açúcar, ensejam outras peculiaridades de implantação como a Casa Grande, a Capela, Engenho e a Senzala (GOMES, 2006, p.20). Na Casa Bandeirista predominam os cheios sobre os vazios (REIS FILHO, 1987, p.21), já os Sobrados de vergas curvadas na sua grande maioria são portugueses, enquanto os de verga reta são holandeses, destacam-se também os Solares e as Casas de Câmara e Cadeia nos sítios urbanos dos três primeiros séculos (REIS FILHO, Op.cit, p.28).

Entre todas as arquiteturas produzidas no período colonial a que era para ser vista era a religiosa, por este motivo as representações construtivas das igrejas demonstram maior requinte e acentuação das transposições europeias (BAZIN, 2010, p.205). A arquitetura religiosa está estreitamente ligada a vinda das Ordens religiosas para o Brasil (TELLES, 2008, p.19). Estas ordens seguem os padrões originais, mas vagarosamente vão tomando rumos próprios até atingir sua maioridade nas Minas Gerais, com Antônio Francisco Lisboa, no século XVIII (BAZIN, 1963, p.139); os materiais e as técnicas 
construtivas misturam técnicas Vitruvianas e Renascentistas com a atmosfera misteriosa da teatralidade Barroca (TIRAPELI, 1999, p.19).

Quanto ao aprender ver o Urbanismo, um dos autores mais importantes nos primeiros trezentos anos foi o Professor Nestor Goulart Reis Filho, seu livro Contribuição ao Estudo da Evolução Urbana do Brasil (1500/1720) publicado em 1968, registrou questões históricas das capitanias e tabelas cronológicas de fundação das cidades no período colonial, documentando a diversidade e complexidade da vida colonial, a política centralizadora que forçava e garantia o controle, os serviços existentes nas cidades e a relação entre as produções exploratórias comerciais e ciclos econômicos.

A arquitetura brasileira, a partir dos finais do século XVIII e início do XX, recebe a influência de outros "ingredientes", tanto da Europa quanto dos Estados Unidos, o Neoclassicismo e os outros revivais são sentimentos nostálgicos e emocionais da Antiguidade. Os modelos utilizados se baseiam nas publicações de obras clássicas, a revalorização das harmonias antigas faz revisitar as lições Palladianas e suas fortunas (KRUFT, 2016, p.445). Essas lições vieram para o Brasil com a Missão Artística Francesa de 1816, com Grandjean de Montigny, Lebreton, os irmãos Taunay, Jean Baptista Debret e muitos outros (BARDI, 1975, p.46); na versão de alguns historiadores e estudiosos da arquitetura, eles romperam com uma possibilidade que vinha se firmando de uma arquitetura genuinamente nacional vislumbrada pelo Barroco das Minas Gerais.

O Ecletismo no Brasil pode ser entendido levando-se em conta a análise da arquitetura de algumas cidades, o Rio de Janeiro adotaria o estilo Chalet que triunfaria e se tornaria o que ficou conhecido por estilo pitoresco, também havia o Neogótico Imperial como no Gabinete de Leitura Português. Em São Paulo exemplos são a Catedral Metropolitana em estilo Neogótico, o Teatro Municipal de São Paulo inspirado na Ópera de Paris e as casas Ecléticas paulistanas; um dos mais importantes arquitetos desse período foi Ramos de Azevedo (BRUAND, 2012, p.39).

No final do XIX o Art Nouveau contaminou avassaladoramente toda a produção de objetos e de materiais de acabamento, seu estilo floreal, todo rebuscado, exagerado ao máximo, a carga decorativa com uma ornamentação reinventada a partir dos repertórios de todas as correntes historicistas surgiu com outra gramática, embora a simplicidade formal não fosse seu ideal, essa arte teve enorme penetração no Brasil; vidros, caixilhos, azulejos e ladrilhos eram seu forte e o grande nome da arquitetura brasileira foi Victor Dubugras (BRUAND, Op.cit., p.46). 
Para alguns autores, a arquitetura Moderna teria sido desencadeada a partir do Art Nouveau. São vários os arquitetos importantes neste momento, como Henry van de Velde, Victor Horta e Hector Guimard, além de Otto Wagner; também deve ser citado Antoni Gaudí; mas os que antecedem o racionalismo são August Perret, Adolf Loos e muitos outros.

$\mathrm{Na}$ maturidade da arquitetura Moderna, os quatro grandes pilares do fazer que devem ser sempre lembrados são: Walter Gropius, Mies van Der Rohe, Frank Lloyd Wright e Le Corbusier (BRUAND, Op.cit., p.35). No Brasil de JK, surgiu Oscar Niemeyer, mas Gregori Warchavchik deve ser sempre mencionado. A grande obra modernista de 1937 é o Ministério da Educação e Saúde (Lucio Costa, Niemeyer, Reidy, Carlos Leão, Ernani Vasconcelos); outros nomes importantes são Vilanova Artigas, Lina Bo Bardi, irmãos Roberto e João Filgueiras Lima, ensejando o denominado "Triunfo da Plástica" (BRUAND, Op.cit., p.151).

Um último ponto sobre o aprendizado básico de saber ver o urbanismo e a arquitetura indica o uso do concreto no Brasil. De acordo com o Livro "O Concreto no Brasil" (VASCONCELOS, 2002, p.13) não se pode precisar quando ele foi usado pela primeira vez, mas a utilização de pré-fabricados refere-se à execução do Hipódromo da Gávea no Rio de Janeiro, na verdade, o século XX envolveu, na sua primeira metade até o seu terceiro quarto, uma harmonia entre a arquitetura e a engenharia marcadas pela ousadia e engenhosidade culminando no projeto urbano e arquitetônico da cidade de Brasília (URBANISMO NO BRASIL, 1999, p.230).

O aprendizado do saber ver o urbanismo e arquitetura através da história e da teoria parecem contemplados (ZEVI, 1996, p.53), no entanto, como e de que forma poderíamos reconhecer todos estes conceitos in situ?

As Viagens Acadêmicas são um recurso indiscutível para se analisar todos esses preceitos com a vantagem de acrescentar a percepção de todos esses elementos no local. Uma cidade capaz de acomodar a maioria desses condicionantes históricos e teóricos citados é a cidade de Penedo, na divisa dos estados de Sergipe e Alagoas, às margens do Rio São Francisco, portanto, a verificação de várias destas teorias, histórias, técnicas construtivas, estilos e as influências dos moradores locais podem ser apreciadas a seguir, frente a uma reflexão crítica exploratória de observação, diferenciada da oferecida na forma tradicional. 


\section{VIAGENS ACADÊMICAS A PENEDO}

A cidade de Penedo, indiferente à precisão da data de sua implantação, que para alguns se deu em 1560 (SOUTO, 2010, p.141), teve como fator determinante a sua localização, ou seja, adentrando alguns quilômetros do delta do São Francisco, sua posição geográfica se deveu, inquestionavelmente, ao controle militar e econômico da região. A fortaleza, que então se assentou num rochedo (Penedo), proporcionava uma ampla e estratégica fiscalização na rota fluvial entre os interiores do Brasil e o mar. Elevada à Vila de São Francisco em 1636, denominada de Penedo do rio São Francisco, atingiu o fórum de cidade em 1842, consolidando-se a época como uma das cidades comerciais mais importantes do Segundo Império (SOUTO, Op.cit., p.142).

A primeira grande referência de aprendizado ao observar o sítio histórico urbano de Penedo, a partir das margens na cidade de Neópolis do lado do Estado de Sergipe, é a possibilidade da constatação da conjugação entre a paisagem natural e a paisagem artificial que o urbanismo definiu como cidade alta e cidade baixa. O Porto e o Paço Imperial de Penedo fazem lembrar, guardada as proporções, do Terreiro do Paço na cidade de Lisboa, com influência do rio (ria) Tejo para Lisboa na mesma escala da importância do São Francisco para a implantação de Penedo. Quanto a engenharia militar portuguesa e holandesa, observa-se a posição estratégica em relação implantação de uma fortificação, pois a sinuosidade, a profundidade e a correnteza do rio São Francisco nesta posição, obrigavam os navios a se colocarem exatamente na linha de tiro dos canhões da cidade sob o risco de encalharem nos bancos de areia (Figura 1)

As cidades são estruturas multifacetadas que, com o tempo, recebem acréscimos, transformações, destruições, alterações, complementações na sua composição, ao vislumbrar o patrimônio ambiental urbano deste sítio chamam a atenção, entre o Paço Imperial e a Igreja de São Gonçalo, o Hotel Modernista de São Francisco, construído por volta de 1960 e a torre do relógio de edificação Art Déco, construída em 1935, que abriga a Associação Comercial. Ao observar estas edificações, nota-se que elas encobrem a vista do Convento Franciscano de Santa Maria dos Anjos e encobrem a vista da Casa de Câmara e Cadeia e, respectivamente, da Catedral de Nossa Senhora do Rosário. Esta questão da interferência visual na ambiência histórica a partir de construções "novas" é uma das discussões mais difíceis no tratamento da preservação das áreas históricas urbanas. 
Figura 1 - Travessia de balsa do lado de Sergipe (jul. 2016, ago. 2019 - acima) e vista da cidade (set. 2016 - abaixo).
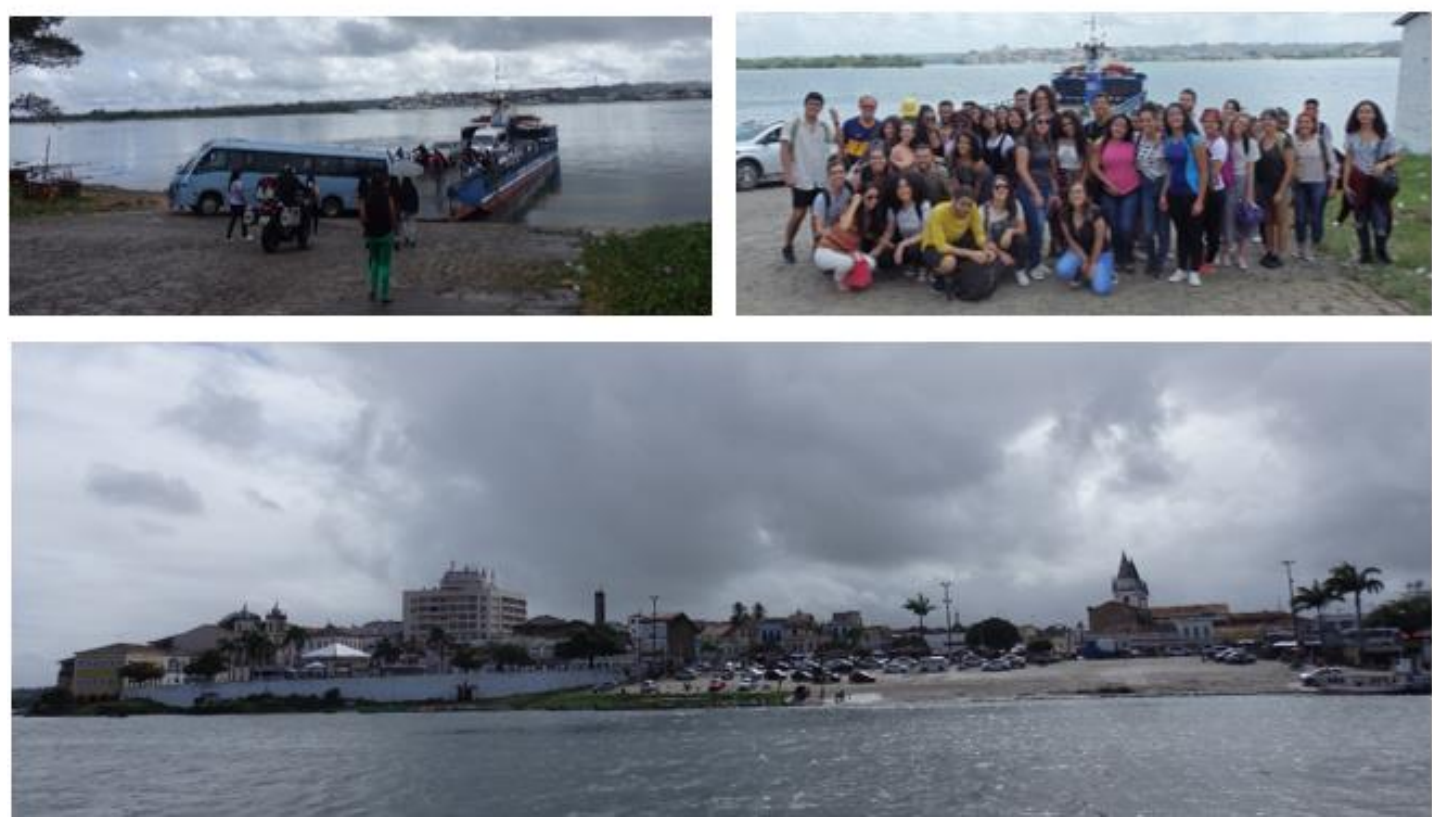

Fonte: Fotos dos autores (2016, 2019).

O Convento Franciscano de Santa Maria dos Anjos e a Igreja tiveram sua construção iniciada no século XVII (BENS MÓVEIS E IMÓVEIS, 1994, p.1). Sua implantação no terreno possui diferenças em relação à implantação de outros conventos franciscanos, como do Convento de Santa Cruz na cidade de São Cristóvão em Sergipe, contudo possui semelhanças com o Convento de Nossa Senhora das Neves em Olinda. O Cruzeiro de Pedra, a frente da Igreja de Santa Maria, é uma das características que se repetem em todos os conventos e igrejas da Ordem Franciscana. O Claustro é composto por colunas circulares nas quais o fuste tem maior diâmetro na parte inferior do que a parte superior, a base e os capitéis possuem influência dórica maneirista ao gosto Palladiano e são arrematadas por arcos abaulados com cartelas no seu centro de aduela enfeitados acima por conchas representativas do Barroco e datadas. A composição interna do conjunto de Santa Maria dos Anjos tem espacialidade padrão do período colonial brasileiro, com coro, grande nave, arco de transição e capela mor; a nave principal é pouco ornamentada, mas diferente do altar mor com colunas salomônicas retorcidas e expediente Barroco.

À margem esquerda do rio São Francisco, os pescadores ergueram, por volta de 1720, uma Capela pedindo proteção contra as traiçoeiras correntezas do "Velho Chico" 
(BENS MÓVEIS E IMÓVEIS, Op.cit., p.2). Esta primeira construção desmoronou e a placa informativa na fachada indica que foi refeita em 1729; a grande altura frontal da igreja em relação a sua largura provoca uma distorção visual, fazendo com que o observador fruidor tenha que se afastar para que a visão do frontispício e frontão não sejam distorcidos. A riqueza artística da Igreja é demonstrada internamente pela azulejaria nas paredes da nave central, dos ladrilhos hidráulicos com motivos florais em seu piso, da imagem de Nossa Senhora pintada no forro abobadado e, altar mor com concheados em sinuosidades exuberantes folheadas em ouro; todo este conjunto levou o célebre estudioso da arquitetura brasileira Germain Bazin declarar: "um conjunto admirável"... “quase desconhecido"..."um dos mais bonitos do Brasil” (1983, p.316).

A Igreja de São Gonçalo Garcia foi edificada sobre a antiga capela entre 1758 e 1759 (BENS MÓVEIS E IMÓVEIS, Op.cit., p.2). Quando observada em sua implantação percebe-se o mesmo problema de equilíbrio da fachada notado na Igreja de Nossa Senhora da Corrente, apesar de haver uma possível simetria entre a largura e altura, a falta de domínio das lições de Brunelleschi em relação à perspectiva produz a impressão de um desequilíbrio visual que se torna acentuado pelo formato das torres em bastiões (baluartes), acentuado pelos grandes coruchéus que ornamentam as duas torres sineiras, as quais, provavelmente, feitas em época diferente da construção da Igreja.

Na parte interna, apesar do forro em gamela não apresentar mais a sua pintura, os púlpitos bem trabalhados, os altares laterais em estilo Neoclássico, a capela mor estreita e profunda marcada no seu início pelo arco cruzeiro, definem uma forte influência da escola Bahiana Colonial, semelhante à Igreja de São Domingos Gusmão e à Igreja de São Pedro dos Clérigos na cidade de Salvador.

No Paço Imperial, em Penedo, observamos um sobrado de características coloniais portuguesas, provavelmente do século XVIII, pois já possui técnicas construtivas mais desenvolvidas do que as casas térreas simples dos primeiros cem anos no Brasil. Entre as características observadas estão a forma quadrada da edificação e sua implantação no limite do terreno, apesar de se tratar de uma edificação colonial com três pavimentos, as paredes não são tão espessas como as utilizadas na arquitetura religiosa e militar. Os vazios (portas e janelas) predominam sobre os cheios (paredes) e, apesar de formato colonial, receberam acréscimos de guilhotinas afrancesadas. $\mathrm{O}$ aspecto do casario do Paço Imperial muda na região do Porto para construções mais estreitas no lote, também 
são edificações assobradadas, que perfazem uma semelhança com as arquiteturas holandesas do Bairro Santo Antônio na cidade do Recife (1630-1654).

A Casa de Câmara e Cadeia na cidade alta é uma construção assente sobre as antigas ruínas da fortaleza, paredes largas, caiadas e janelas com gradis na parte térrea expressam as características construtivas portuguesas da metade do século XVIII. Na frente da Casa de Câmara e Cadeia fica uma pequena construção, datada em sua cartela acima da portada principal de 1769 , este local servia as últimas orações dos condenados que seriam enforcados no Terreiro do Paço.

Nas ruas próximas, apesar de existirem edificações residenciais com aspectos tipológicos coloniais, a arquitetura recebe contributos de outras épocas, como o Hotel São Francisco em que o uso do concreto denota uma arquitetura totalmente diferente do espaço histórico urbano colonial; assim como, ao lado do Hotel, as superfícies das paredes da Associação Comercial, com reboco em área quartzosa (mica e feldspato), fazem as linhas de força brilharem sob o sol e expressam uma das principais características da arquitetura Art Déco.

Na avenida Floriano Peixoto, logradouro atrás da avenida que compreende o Paço Imperial e o Porto, destacam-se duas arquiteturas, a do Teatro Sete de Setembro e o Mercado Público.

O Teatro, em estilo Neoclássico, projeto realizado pelo arquiteto Italiano Luiz Lucarine (o mesmo que projetou o Teatro de Maceió), sua construção começou em 1878 e terminou em 1884 (Placa informativa na fachada da edificação). O Mercado Municipal possui a parte externa em estilo Eclético predominando o Neorrenascentista adaptado a um interior colonial representativo de antigos trapiches de açúcar (depósitos de açúcar).

O maior conjunto arquitetônico representativo do Ecletismo, Art Nouveau, Art Déco, se encontra na avenida Getúlio Vargas, praticamente fora da área Histórica do Paço Imperial e do Porto; este conjunto representativo do final do século XIX até a metade do XX na avenida Getúlio Vargas, juntamente com todo o espaço da arquitetura Colonial na área urbana de Penedo, distinguem, pormenorizam e retratam um registro e uma documentação cultural de excepcional importância do Brasil (Figura 2).

Figura 2 - Exemplares da Arquitetura de Penedo Legenda: a- Convento de Santa Maria dos Anjos (jul. 2016); b- Igreja de Nossa Senhora da Corrente (jul. 2016); c- Igreja de São Gonçalo (set. 2016); d- Matriz de Nossa Senhora do Rosário (set. 2016); e- Oratório dos Condenados (abr. 2012); f- Casa de Câmara e Cadeia (mar. 2017); g- Teatro Sete de Setembro (mar. 2017); h- Mercado Municipal (ago. 2019); i- Casa 
Eclética (ago. 2019); j- Casa Art Nouveau (ago. 2019); k- Associação Comercial Art Déco (set. 2016); l- Hotel São Francisno Contemporâneo/Moderno (set. 2016).
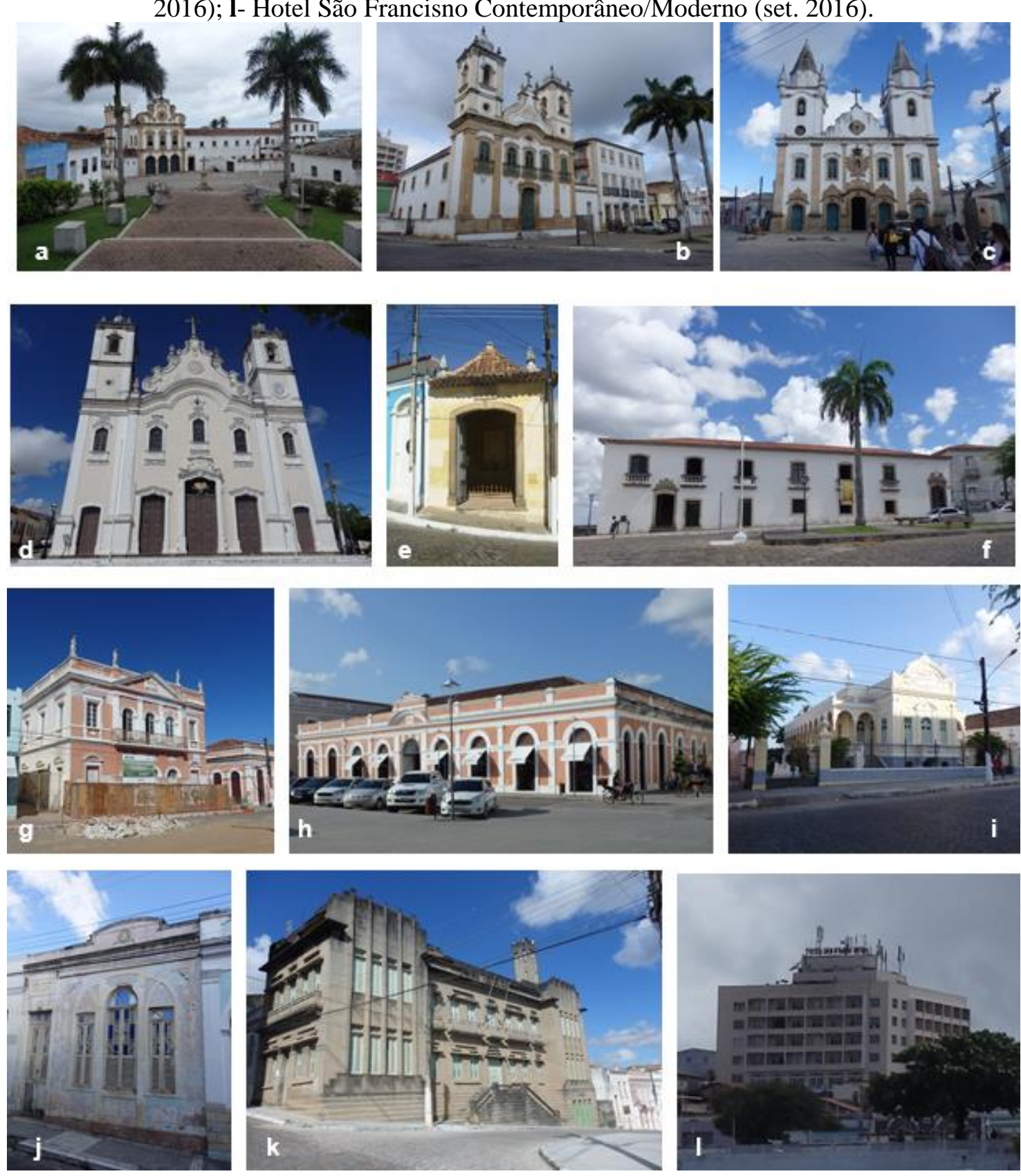

Fonte: dos autores $(2012,2016,2017,2019)$

\section{PERCEBENDO O QUE NÃO HAVIA SIDO PERCEBIDO}

No Conjunto do Convento de Santa Maria dos Anjos, a fachada principal com ornamentos esculpidos em pedra calcária em adornos antropomórficos apresenta no frontão volutas salientes com desenhos de figuras humanas a segurar, como atlantes, a curvatura da espiral, esta composição representada por soldados portugueses com túnicas e saiotes indígenas retratam a etnologia que se repete em tema escultórico no interior da 
Igreja; no centro do frontão a composição da figura humana, especialmente nos anjos talhados acima do óculo em estilo floral seguram a cartela que traz o nome da Virgem Protetora, retratam a técnica da proporção humana da arte Maneirista (JANSON, 1993, p.670).

Na Sacristia, ao lado da Igreja, por onde também se adentra ao Convento, tem-se um altar cujo tema esculpido, de Atlantes segurando a base da mesa central representam em suas faces os povos portugueses, índios e negros, notados pela composição dos cabelos, dos narizes, da forma do rosto e especialmente dos olhos; as cores predominam os vermelhos e azuis. O tema dos anjos voantes segurando o Brasão da Ordem Franciscana se repete no arco cruzeiro, agora esculpido em madeira policromada, possuem traços Maneiristas e Barrocos muito mais elaborados, demonstrando uma qualidade técnica de escultura em madeira muito mais desenvolvida do que a escultura em pedra.

O forro da Igreja de Santa Maria dos Anjos apresenta uma das poucas pinturas ilusionistas ainda remanescentes (OTT, 1982, p.12), assinada em 1784 por Libório Lazdro Lial Afes, retrata a Virgem Protetora, o observador fruidor, que adentra a Igreja pelo avarandamento e passa abaixo do coro, ao se posicionar na entrada da nave principal e olhar para Santa Maria pintada no forro, verá que ela abre os braços para recebê-lo, ao caminhar em direção à capela mor e altar mor para receber as bençãos da eucarístia, na cancela abaixo do arco cruzeiro, ao se virar e contemplar novamente a pintura do forro perceberá que a Virgem se voltou para ele e mantém seu braços abertos como a declarar sua eterna proteção misericordiosa.

Os materiais construtivos, como o piso da Igreja de Santa Maria, demonstram as alterações que se fizeram ao longo do tempo, ou seja, aparecem na composição ladrilhos hidraulícos ingleses do inicio século XX (placa informativa na Sacristia), estas alterações nos interiores das Igrejas brasileiras, especialmente do Nordeste, devem-se a noções higienistas do século XIX. Em Penedo, os ladrilhos hidraúlicos ingleses também podem ser apreciados no piso da Igreja de Nossa Senhora da Corrente, no entanto, com desenhos muitos mais elaborados, especialmente no centro da nave principal, no entanto, são os azulejos das paredes e o altar mor conjuntos de especial unidade artística; os azulejos retratam várias fases da vida da Virgem Maria, como seu casamento, a anunciação e a fuga para o Egito. 
Os retábulos da Igreja de Nossa Senhora da Corrente possuem imagens de São José, Santa Lucia e Santa Cecília, além, é claro, da imagem de Nossa Senhora da Corrente com o Menino Jesus nos braços. Categoricamente, é um templo dedicado às mulheres, pois além da representação da vida da Virgem Santíssima traz no coroamento dos altares colaterais esculturas de Judite com a cabeça de Holofernes (BIBLIA SAGRADA, Cap. 1 e 2 Livro de Judite, 1996, p.539) e de Jael com o escopo das armas com o qual matou Sisara (BIBLIA SAGRADA, Cap. 4 e 5 do Livro dos Juízes, 1996, p.280).

O púlpito também é um dos elementos de maior destaque junto com o altar mor, tem a base representando a coroa da Virgem Santíssima e o corpo em fingidos de mármore rosáceis, os quais proliferam pelo altar junto com laqueaduras douradas em folhas de ouro e azuis preponderantes embrechados nos retorcimentos Barrocos e Rococós das colunas salomônicas que compõem de forma a dialogar com os azuis e brancos do conjunto azulejar. O forro possui pintura da Virgem Santíssima ao centro com raios de luz, declarada como pintura ilusionista, infelizmente não se pode constatar esta técnica, provavelmente devido a intervenções restauradoras que danificaram este efeito ótico.

A Igreja de Nossa Senhora da Corrente tem sua história relacionada a duas questões: a Mãe de Deus para a proteção dos pescadores e a um fugitivo de Portugal que chega a Penedo algemado alcançando a graça de se libertar e, em devoção a este livramento, edificou a Igreja enterrando em seu alicerce um pedaço da corrente; entretanto, importante é sua relação com o movimento abolicionista, pois em um dos altares laterais, esquerdo de quem adentra na Igreja, existe uma passagem secreta para esconder os escravos que fugiam das fazendas e posteriormente se abrigariam no Quilombo de Palmares. Igrejas como a de Comandaroba (1734) na cidade de Laranjeiras e da Matriz do Senhor dos Passos (1848) na cidade de Maruim, ambas em Sergipe, são representações marcantes desta estratégia arquitetural abolicionista.

A relação da arquitetura com a representação das Ordens religiosas é indissociável, em Penedo percebe-se a presença marcante dos franciscanos, mas também a presença de Irmandades como dos negros e dos pardos que se funde aos franciscanos.

A Igreja de São Gonçalo Garcia dos Homens Pardos relaciona-se à história deste Santo que pertencia a Ordem de São Francisco e considerado o primeiro santo pardo (VIANNA, 2016, p.39), por ser músico, rezam as lendas que tocava em prostíbulos para persuadir as mulheres a não praticarem seus ofícios e os homens a não fornicarem (Figura $3)$. 
Figura 3 - Detalhes da Arquitetura de Penedo

Legenda: a- Frontão Santa Maria (ago. 2019); b- Altar Sacristia Santa Maria (set. 2016) ; cArco Cruzeiro Santa Maria (abr. 2012); d- Coluna Salomônica Altar Santa Maria (abr. 2012); eForro Santa Maria (jul. 2016); f- Piso Santa Maria (set. 2016); g- Pìso Igreja da Corrente (abr. 2012); h- Jael, Igreja da Corrente (set. 2016); i- Judith, Igreja da Corrente (set. 2016); jAberturta falsa no altar colateral, Igreja da Corrente (set. 2016); k- Forro, Igreja da Corrente (set. 2016); l- Azulejos, Casamento da Virgem Maria Igreja da Corrente (mar. 2017); m- Torres de São Gonçalo (mar. 2017) n- Zéfiro, Igreja de São Gonçalo (jul. 2016).
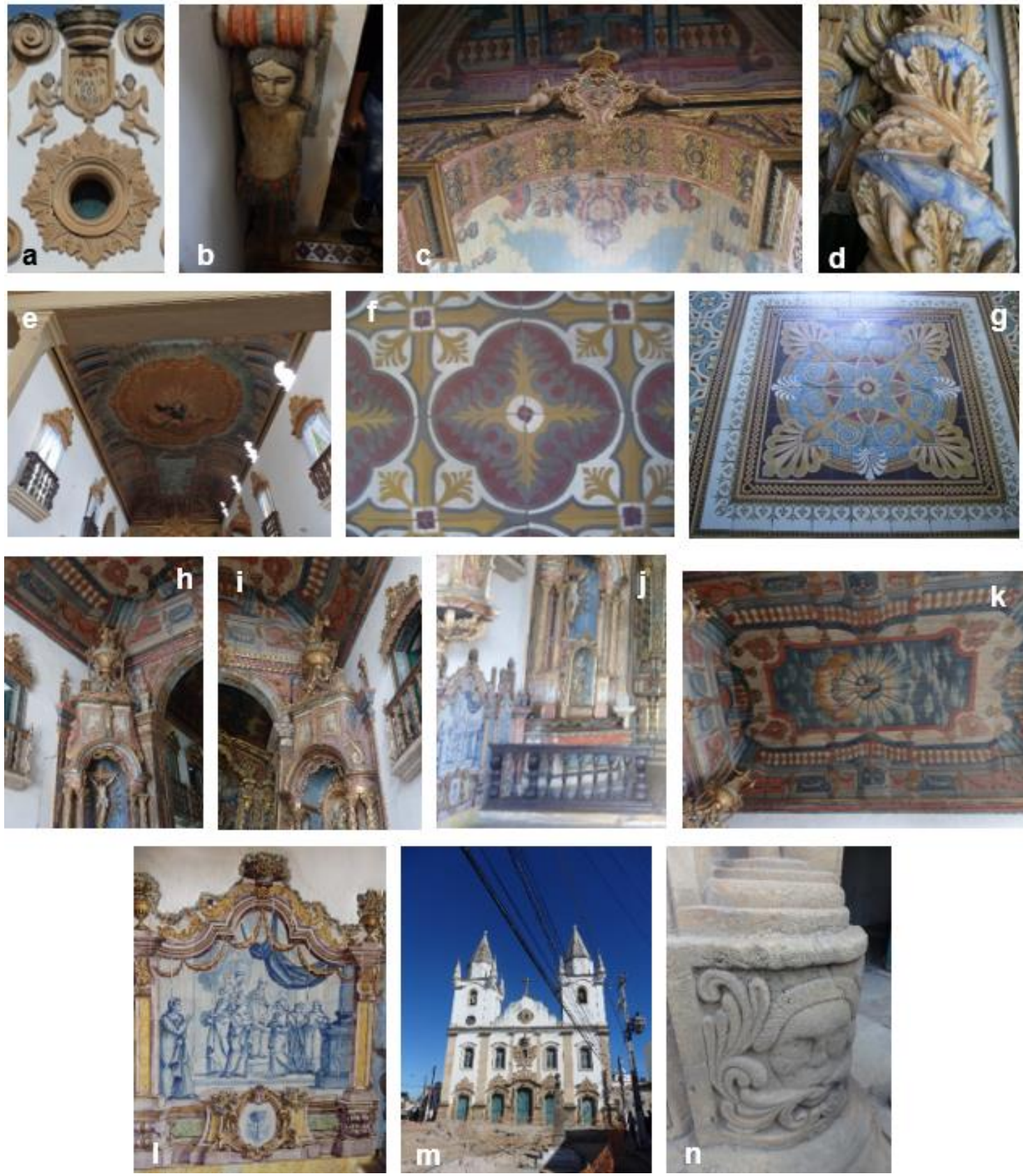

Fonte: dos autores $(2012,2016,2017,2019)$

A irregularidade proporcional da fachada da Igreja de São Gonçalo Garcia e suas torres é elemento que chama a atenção, no entanto, a talha escultórica constituida por 
figuras antropomórficas (carrancas), esculpidas nas ombreiras e bases das pilastras das portadas, possuindo uma linguagen espanholada, apesar da distância com o plateresco que pode ser visto na Igreja de São Francisco da Ordem Terceira de Salvador, representam faces de figuras humanas cuja forma da cabeça e dos narizes recaem na fisionomia representativa dos homens negros e especialmente pardos, esta representatividade se expressa por uma figura na base da portada principal representando Zéfiro, o Deus Grego dos ventos. A parte interna da Igreja de São Gonçalo Garcia, apesar de haver perdido muito de suas ornamentações e pinturas, como no forro, tem as esculturas que encimam os altares laterais o mesmo tema de Judite e Jael, ofertados na Igreja de Nossa Senhora da Corrente.

As sensações vividas in situ no espaço urbano são elementos de grande aprendizado na arquitetura, um dos exemplo desta questão é a fruição da visão do rio São Francisco a partir da comadreira de uma das janelas da Casa de Câmara e Cadeia (Casa da Aposentadoria no Largo do Pelourinho). Nesta situação se pode exercitar a imaginação de como os soldados holandeses guardavam e monitoravam a passagem dos navios pelas águas de cor esmeralda do "Velho Chico". A Casa de Câmara e Cadeia possui alvenaria de pedra rebocada com argamassas a base de cal, diferente da técnica construtiva observada em algumas casas coloniais de Penedo, cujas paredes são feitas em taipa de sebe (taipa de mão), como na residência que hoje abriga a sede do IPHAN na avenida Floriano Peixoto.

Na percepção do que não havia sido percebido, a arquitetura contemporânea do Hotel de São Francisco alguns elementos tentam reproduzir conceitos da arquitetura moderna, como os pilotis e uso do concreto, no entanto, são apenas aspectos que não atigem com substancialidade o programa moderno; resultado diferente se tem no Teatro Sete de Setembro, onde as Musas da Arte, ou seja, as Deusas da Música, da Poesia, da Pintura e da Dança, feitas em louça, encimam a platibanda, seu interior nos faz retornar aos antigos recintos do período Romântico na Inglaterra e na França. O Mercado em estilo Eclético aguça os cheiros, sabores, ruídos, tatos, de uma percepção humana existencial materializada na espacialidade da arquitetura.

As construções da Avenida Getulio Vargas são exemplos de colagens historicistas de vários revivais formando um dos conjuntos mais completos de edificações assobradadas do período Eclético no Brasil. Neste conjunto, percebe-se uma edificação Art Déco na forma de barco exatamente igual a encontrada na Praça Camerino na região 
central da cidade de Aracaju, na cor azul clara, perfazendo o que podemos conceituar como várias influências advindas de revistas, jornais, livros e folhetins dos séculos XIX e XX (Figura 4).

Figura 4 - a- Vista do rio São Francisco da Casa de Câmara e Cadeia (mar. 2017); bMáquina de acetileno na Igreja do Rosário (jul 2016); c- Parede de Taipa de Sebe sede do IPHAN (jul. 2016); d- Igreja do Rosário (mar. 2017); e- Art Déco/racionalismo perto da Igreja do Rosário (set. 2016); f- Interior do Teatro Sete de Setembro em restauração (set. 2016); gDeusas da Arte no Sete de Setembro em restauração (set. 2016); h- Casa Barco av. Getúlio Vargas (ago. 2019); i- Chalé av. Getúlio Vargas (ago. 2019); j- Neogótico av. Getúlio Vargas (ago. 2019).
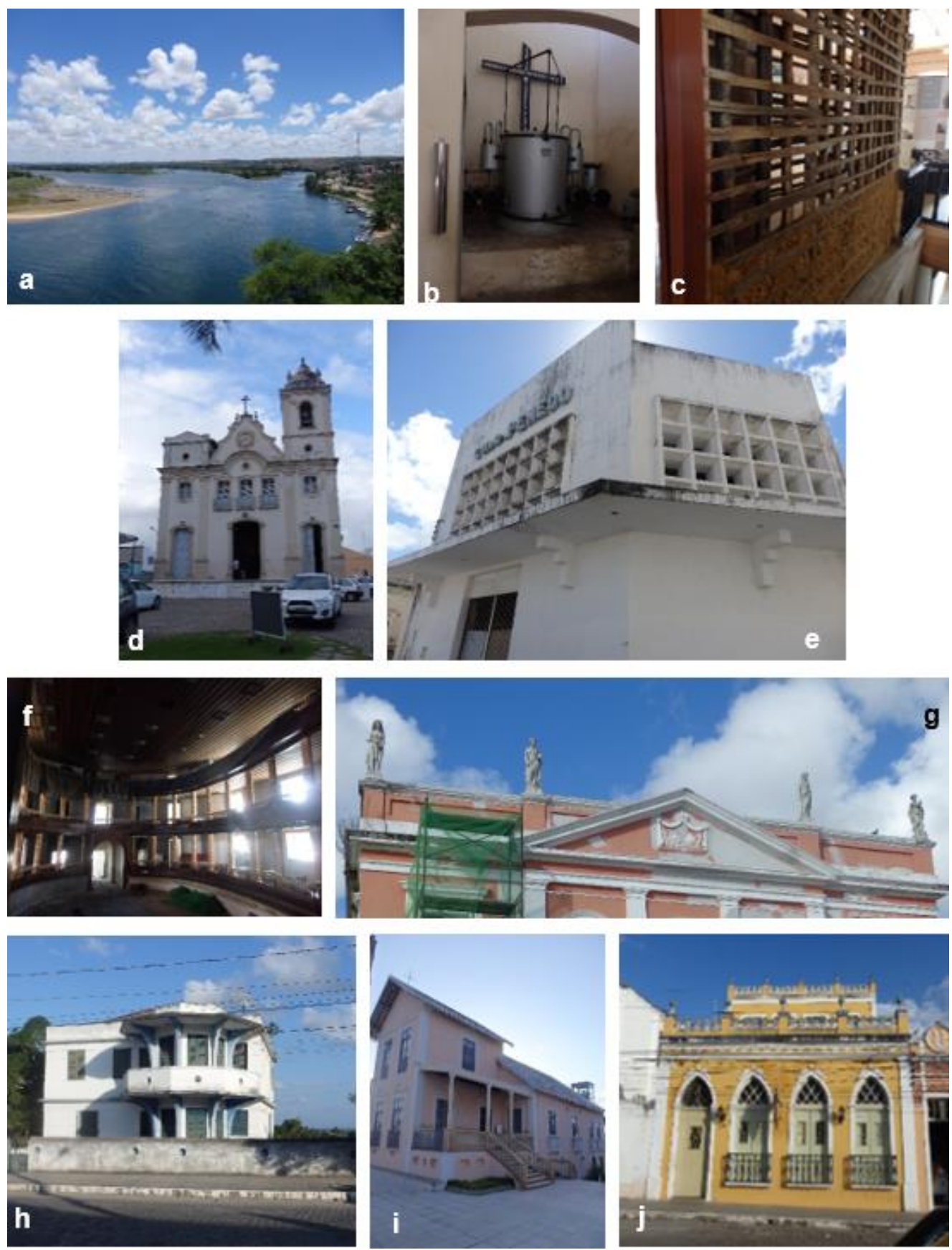

Fonte: dos autores $(2012,2016,2017,2019)$ 
Propositalmente, deixamos para falar da arquitetura negra em Penedo no final deste artigo, pois é neste momento que podemos exercitar o conceito de perceber o que não havia sido percebido. Se analisarmos o espaço urbano de Penedo, temos uma área histórica colonial com acréscimos de edificações do final do XIX e início do XX, e uma área mais afastada com edificações Ecléticas, Art Nouveau e Art Déco, então onde estariam as construções representativas dos negros? Há alguns anos temos analisado a cidade colonial de São Cristóvão e a cidade Imperial de Laranjeiras no estado de Sergipe, onde as Igrejas da Ordem dos Pretos como do Rosário e São Benedito ficam mais na periferia da área histórica.

Penedo segue este modelo, ou seja, a Catedral de Nossa Senhora do Rosário e a Igreja Matriz de Nosssa Senhora do Rosário dos Pretos, ficam em separado dessas áreas históricas, apesar da Matriz estar no Largo do Pelourinho, praticamente ao lado da Casa dos Aposentados (Câmara e Cadeia), esta construção de grandes proporções é voltada para a Rocheira, apesar de ser fruto de assentamentos sobre capelas anteriores, apenas terá sua construção entre 1808 e 1899, o que a coloca, devido as suas sucessivas reformas, em separado dos demais conjuntos analisados, apesar de elementos arquitetônicos de muito interesse patrimonial, como a torre sineira e seu frontão.

A Igreja de Nossa Senhora do Rosário dos Pretos, mais afastada, entre área colonial e a área Eclética, também possui arquitetura simples, concluida no século XIX, destacando no seu interior uma máquina de gás acetileno que provia a iluminação elétrica urbana da cidade; possui uma torre inconclusa e interior simples e singelo, quanto a sua espacialidade chama a atenção sua proximidade com uma edificação Art Déco/racionalista que servia ao antigo Cine Penedo. Estas observações fruidas in situ provocam a hipótese que, apesar dos escravos terem sido os principais construtores da cidade de Penedo, esta comunidade vivia praticamente em uma espacialidade em separado do restante do conjunto patrimonial da cidade.

\section{CONSIDERAÇÕES FINAIS}

As Viagens Acadêmicas proporcionam mais do que a conferência dos conhecimentos adquiridos em referências bibliográficas, ela possibilita o exercício da 
percepção de questões que só podem ser fruidas no local, ou seja, elementos estruturais, elementos técnicos, elementos ornamentais, cores, relações com o imaginário da população local e, principalmente, adaptações às necessidades e disponibilidade da sociedade no seu tempo; a observação exploratória age sobre a memória do observador fruidor, deixa marcas, constroi entendimentos com outros locais e outras arquiteturas, reforça o caráter da identidade e memória, atuando na formação mais completa dos futuros profissionais, além de registrar elementos que, na maioria das vezes, não foram completamente percebidos pelos estudiosos da história e teoria da arquitetura e urbanismo.

\section{REFERÊNCIAS}

BARDI, P. M. História da Arte Brasileira: Pintura, Escultura, Arquitetura e outras artes. São Paulo: Melhoramentos, 1975.

BAZIN, G. A arquitetura religiosa barroca no Brasil. Rio de Janeiro: Record, 1983. v.2.

BAZIN, G. Barroco e Rococó. Tradução Álvaro Cabral; revisão Hildgard Feist - 2ª ed. São Paulo: Editora WMF Martins Fontes, 2010.

BAZIN, G. O Aleijadinho e a escultura Barroca no Brasil. 2ª ed. Rio de Janeiro: EDITORA RECORD, 1963.

BENS MÓVEIS E IMÓVEIS inscritos nos Livros do Tombo do Instituto do Patrimônio Histórico e Artístico Nacional. 4aa ed. Rio de Janeiro/Ministério da Cultura, 1994.

BIBLIA SAGRADA. 104aa ed. São Paulo: Editora AVE-MARIA, 1996. [Cap. 1 e 2 Livro de Judite, p.539 - Cap. 4 e 5 do Livro dos Juízes, p. 280].

BRUAND, Y. Arquitetura contemporânea no Brasil. São Paulo: Perspectiva, 2012.

BURY, J. Arquitetura e arte no Brasil Colonial. Org. Myriam Ribeiro de Oliveira: tradução [Isa Mara Lando]. São Paulo: Nobel, 1991.

ECLETISMO na Arquitetura Brasileira. (org.) Annateresa Fabris. São Paulo: Nobel, 1987.

GOMES, G. Engenho e arquitetura. Recife: Fundaj, ed. Massagana, 2006.

HUE, J. de S. Uma visão da arquitetura colonial no Brasil. Rio de Janeiro: AGIR, 1999. 
JANSON, H. W. História Geral da Arte. São Paulo: Martins Fontes, 1993.

KRUFT, H.-W. História da Teoria da Arquitetura. Tradução de Oliver Tolle. São Paulo: EDUSP, 2016.

OTT, C. A Escola Bahia de Pintura 1764-1850. São Paulo: Raizes Artes Gráficas, 1982.

POLIÃO, M. V. Da Arquitetura/Marco Vitrúvio Polião. Tradução e notas Marco Aurélio Lagonegro. São Paulo: HUCITEC; Fundação Para a Pesquisa Ambiental, 1999.

REIS FILHO, N. G. Evolução Urbana do Brasil (1500/1720). São Paulo: Pioneira, 1968.

REIS FILHO, N. G. Quadro da arquitetura no Brasil. São Paulo: Editora perspectiva, 1987.

RODRIGUES, J. W. A casa de moradia no Brasil antigo. Revista do

SPHAN/Ministério da Educação e Saúde, n. 9, p.164-198, 1945.

RODRIGUES, J. W. Documentário arquitetônico relativo a antiga construção civil no Brasil. 2ª ed. São Paulo: Martins, Editora da Universidade de São Paulo,1975.

SEGAWA, H. Arquitetura no Brasil 1990-1990. São Paulo: Editora da Universidade de São Paulo, 1997.

SILVA-NIGRA, D. C. M. Francisco de Frias da Mesquita, Engenheiro-mor do Brasil. Revista do SPHAN/Ministério da Educação e Saúde, Rio de Janeiro, n. 9, p.9-84, 1945.

SMITH, R. C. Arquitetura civil do período colonial. Revista do PHAN/Ministério da Educação e Cultura, n.17, p. 27-126, 1969.

SOUTO, C. B. A importância da realização de eventos em municípios de valor histórico: um estudo sobre Penedo/Alagoas e a realização do festival de Cinema (19751982). In: RIBEIRO, M. (Org.). Olhares sobre o patrimônio cultural: reflexões e realidades. Porto Alegre, RS: Asterisco, p.133-153, 2010.

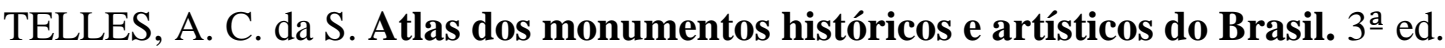
Brasília, DF: IPHAN/Programa Monumenta, 2008.

TIRAPELI, P. As mais belas igrejas do Brasil. São Paulo: Metalivros, 1999.

TOMBAMENTO DO CONJUNTO URBANO DE PENEDO. Disponível em: http://portal.iphan.gov.br/pagina/detalhes/110. Acesso em: 23 de set. 2021.

URBANISMO NO BRASIL - 1895-1965. [Coordenadora] Maria Cristina da Silva Leme. São Paulo: Studio Nobel; FAUUSP, FUPAM, 1999.

VASCONCELOS, A. C. de. O Concreto no Brasil. São Paulo: Nobel, 2002. 
VIANNA, L. Gonçalo Garcia: identidades e relações raciais na história de um santo pardo na América portuguesa. Rio de Janeiro: Open Edition Press, 2016. p. 39.

WEIMER, G. Arquitetura indígena: sua evolução desde sua origem asiática. Porto Alegre: Edigal, 2018.

WEIMER, G. Inter-relações afro-brasileiras na arquitetura. Porto Alegre: EDIPUCRS, 2014.

ZEVI, B. Saber ver a arquitetura. 5a ed. São Paulo: Martins Fontes, 1996. 